\title{
REFERENCIAL DE CUIDAR EM ENFERMAGEM PSIQUIÁTRICA: UM PROCESSO DE REFLEXÃO DE UM GRUPO DE ENFERMEIRAS
}

\author{
Psychiatric Nursing Care Reference: A Reflective Process of a \\ Group of Nurses
Referencial de Cuidar en Enfermería Psiquiátrica: un proceso de reflexión de un grupo de enfermeras

Anna Cristina Cardoso Fontes dos Santos ${ }^{1}$

\begin{abstract}
RESUMO
Estudo qualitativo que teve como objetivo construir, em conjunto com seis enfermeiras chefes de uma instituição psiquiátrica pública no Rio de Janeiro, um referencial teórico-filosófico a ser implantado por elas próprias, no desenvolvimento do processo de cuidar de pacientes psiquiátricos. Realizou-se um processo de reflexão sobre dinâmica de grupo, buscando autoconhecimento e amadurecimento. Tal processo desenvolveu-se durante a construção de dissertação de Mestrado desta autora, orientada pela Dr ${ }^{a}$ Eloita Pereira Neves. Utilizaram-se conceitos das Teorias Humanística e Cuidado Burocrático, diretrizes da Reforma Psiquiátrica e Políticas de Saúde Mental. Os dados obtidos foram gravados, transcritos e analisados de acordo com a análise de conteúdo. Dos resultados emergiram categorias de concepções sobre: Ser Humano; Cuidado Profissional de Enfermagem; Cuidador Profissional; Processo Educativo e Institucional; e Descuidado, que permitiram formular uma proposta de referencial para a prática do Cuidar em Enfermagem para pacientes psiquiátricos de longa permanência institucionalizados.
\end{abstract}

Palavras-chave: Cuidado de Enfermagem. Educação. Enfermagem Psiquiátrica. Pesquisa Qualitativa.

\begin{abstract}
Qualitative research that had as purpose to construct in conjunction with six head nurses, of a public Psychiatric Institution located in Rio de Janeiro, a theoretical-philosophical reference to be implemented by themselves, in the development of the psychiatric patients' care process. It was made a reflexion process on group dynamics looking for self-knowledge and maturity. This occurred during the development of master thesis ${ }^{(1)}$, advised by Dr. Eloita Pereira Neves. It was used concepts of Humanistic ${ }^{(2)}$ and Bureaucratic Care Theories ${ }^{(3)}$, directives of the Psychiatric Reform and Politics of Mental Health. The data collected were recorded, transcribed, and analyzed according to the content analysis ${ }^{(4)}$. The results pointed to categories of Conceptions related to: Human Being; Professional Nursing Care; Care of the Professional Caregiver; Caring as an Educational Process; Institutional and Carelessness. These allowed formulating a reference proposal for the Nursing Care practice in institutionalized psychiatric patients of long permanence.
\end{abstract}

Keywords: Beware of Nursing. Education. Psychiatric Nursing. Qualitative Research.

\section{Resumen}

Investigación cualitativa que tuvo como objetivo construir con seis enfermeras jefes, de una Institución Psiquiátrica pública en Río de Janeiro, una referencia teórico-filosófica a ser implantada por ellas propias, en el desarrollo del proceso de cuidar de pacientes psiquiátricos. Se realizó un proceso de reflexión sobre la dinámica de grupo buscando el autoconocimiento y maduración. Esto se desarrolló durante la construcción de mi disertación de Maestría ${ }^{(1)}$, impulsada por la Dr ${ }^{2}$ Eloita Pereira Neves. Se utilizó conceptos de las Teorías Humanística (2) y Cuidado Burocrático ${ }^{(3)}$, directrices de la Reforma Psiquiátrica y Políticas de Salud Mental. Los datos obtenidos fueron grabados, transcritos y analizados de acuerdo con la analisis del contenido ${ }^{(4)}$. Los resultados destacaron categorías acerca de Concepciones sobre: Ser Humano, Cuidado Profesional de Enfermería; Cuidador profesional; Proceso Educativo; Institucional y des-cuidado que permitieron formular una propuesta de referencia para la práctica del Cuidar en Enfermería a pacientes psiquiátricos institucionalizados de larga permanencia.

Palabras clave: Cuidado de enfermeria. Educación. Enfermería psiquiátrica. Investigación Cualitativa.

'Enfermeira, Mestre em Enfermagem, especialista em Administração em Serviços de Saúde, Gerência em Enfermagem e MBA em Gestão em Saúde, Professora da UNESA, Coordenadora Administrativa e Financeira, Vice-diretora do IMAS Juliano Moreira. Brasil. E-mail: annacardoso@yahoo.com.br 


\section{INTRODUCÃO}

As novas políticas de Saúde Mental incitam um movimento em direção à expansão, à experimentação e ao desempenho das ações da Enfermagem Psiquiátrica, estimulando mudanças no modo de cuidar, voltadas para a relação humana, através da experiência vivenciada. A Enfermagem Psiquiátrica deve acompanhar os movimentos de transformação da psiquiatria, em que o profissional não deixa de ter sua especificidade, mas passa a ter um lugar legítimo na equipe multidisciplinar, reorientando sua prática, com propostas de atividades terapêuticas compartilhadas, voltadas para o hábito de trabalho em equipe, em que são sociabilizados experiências e enfrentamentos dos problemas; restabelecendo a relação do paciente psiquiátrico como sujeito ativo, dando-lhe direitos e capacidade da palavra; diluindo a relação de poder e transformando o modo de viver, cuidando desse ser humano em sofrimento mental, ajudando-o a viver de uma maneira mais digna. Essas transformações desenvolvem-se também pela reflexão cotidiana das ações realizadas pela Enfermagem e pelo desejo de mudar para um saber/fazer/pensar/ser mais e melhor.

A Reforma Psiquiátrica questiona a Instituição Psiquiátrica, o conceito da doença mental e a maneira de lidar com ela. Enfrentar os mitos em relação à doença mental é um desafio diário de cada enfermeiro individualmente para o rompimento de preconceitos, rótulos e estigmas. Por meio do processo educativo, podemos possibilitar a conscientização e participação ativa e transformadora da prática do Cuidar em Enfermagem a pacientes psiquiátricos de longa permanência institucionalizados. Tal prática, permeada pelo respeito, sensibilidade e compromisso autêntico, constitui-se em tentativa de desconstrução das bases que por muito tempo têm sustentado a prática assistencial tradicional da Enfermagem Psiquiátrica nas instituiç̧ões asilares.

Este recorte da dissertação de Mestrado orientada pela Dra. Eloita Pereira Neves faz uma reflexão conjunta sobre as concepções teórico-filosóficas do grupo de enfermeiras, seus conceitos, valores e crenças que permeiam a prática diária do Cuidar em Enfermagem.

\section{FUNDAMENTAÇÃO TEÓRICA}

As Teorias de Enfermagem inter-relacionam conceitos ou ideias as quais, por meio de definições, expressam formas diferentes e significativas para se descrever, encarar ou classificar um fenômeno para a prática. Assim, neste estudo, encontramse articulados alguns conceitos sobre encontro dialógico ${ }^{2}$, sobre a dialética do cuidar burocrático ${ }^{3}$ e sobre a Reforma Psiquiátrica que vem ocorrendo na área de Saúde Mental no Brasil. Além dessas ideias, colaboraram na fundamentação teórica deste estudo diversos autores ${ }^{5-11}$.

Alguns autores afirmam que cuidar é um processo interativo entre ser o cuidado e cuidador, sendo necessário envolvimento para compreensão do seu significado ${ }^{5,6,10}$. Cuidar do outro é antes de tudo cuidar de si ${ }^{11}$. 0 cuidar deve levar a pessoa a alcançar o conforto enquanto cuida, e conforto envolve relacionamento humano $0^{6}$. Cuidado é um processo em que se ajuda o outro a crescer, através da confiança mútua e de uma transformação qualitativa no relacionamento ${ }^{5}$.

A Teoria da Enfermagem Humanística ${ }^{2}$ inspira-se na fenomenologia existencialista, na qual se enfatiza a construção de um mundo melhor, o viver no mundo, o significado da vida como ela é vivida, o campo perceptivo, a natureza do diálogo, 0 potencial humano, a intersubjetividade, o encontro, a presença, o relacionar-se, que corresponde a estar com e fazer com, a relação Eu-Tu (sujeito-sujeito), o modo de ser e de fazer algo, - estar peculiar do indivíduo na luta do sere vir-a-ser, a estar com, ser mais, ser melhore o compromisso autêntico. A filosofia existencialista alude, com ênfase, que o homem se faz por suas escolhas. Ele é um vir-a-ser constante sem nunca atingi-lo na sua plenitude, engajado consigo mesmo, trilhando o caminho que leva ao Ser. 0 enfermeiro engajado aceita sua situação como um ser-no-mundo, será uma presença para os outros e não se contentará em exercer um papel sem compromisso.

A Enfermagem Humanística ${ }^{2}$ valoriza a natureza intersubjetiva do Ser, enfatizando a Enfermagem como uma maneira especial de relacionamento humano, e o significado da vida como ela é vivida, a natureza do diálogo, o ser mais/ melhor, o viver melhor no mundo. Essas enfermeiras foram influenciadas em seus trabalhos pelos existencialistas, humanistas e fenomenólogos. As autoras Stefanelli ${ }^{12} \mathrm{e}$ Travelbee ${ }^{13}$ falam da comunicação interpessoal, que complementa, com dados significativos, fatores da relação interpessoal ${ }^{13}$. Ambas, com suas próprias denominações, abordam a relação dialógica/terapêutica/ajuda/interpessoal de tornar-se uma pessoa melhor no encontro - Cuidar, da mesma forma que Paterson $\&$ Zderad² abordam, em sua teoria, suas bases filosóficas.

A Teoria do Cuidado Burocrático ${ }^{3}$ discute a luta de forças antagônicas em uma instituição burocrática, como o hospital, que podem facilitar ou dificultar o cuidado. Esta síntese dialética do cuidar burocrático tem como tese o cuidar humanístico, educacional, ético e espiritual e como antítese (burocracia) 0 cuidar econômico, político, legal e tecnológico. Esses componentes fazem parte do gerenciamento organizacional de uma instituição.

A Reforma Psiquiátrica é um processo de reflexão e transformação nos diferentes níveis assistenciais, culturais, políticos, econômicos e conceituais que por mais de dez anos vem num crescente movimento de desmistificar o estigma da doença mental e, principalmente, garantir o direito da cidadania a essas pessoas para que possam viver melhor no mundo. As forças antagônicas da Teoria do Cuidado Burocrático ${ }^{3}$ estarão sempre presentes na instituição asilar, porém, a fundamentação para a prática do Cuidar em Enfermagem dos pacientes de longa permanência institucionalizados deverá unir conceitos 
da Teoria Humanística², diretrizes da Reforma Psiquiátrica e as novas Políticas de Saúde Mental - de uma prática transformadora e com participação ativa do sujeito nestas três áreas conceituais.

Além desses conceitos, foram formuladas algumas crenças, adotando como base as próprias conjeturas desta autora formuladas a partir de reflexões originadas da experiência pessoal, da literatura e da discussão com a orientadora. Estas crenças, que corroboraram a fundamentação deste estudo e foram compartilhadas com as participantes dos seminários, incluem os conceitos de: Ser Humano, Saúde/Doença/Saúde Mental, Ambiente/IMASJM/Sociedade, Enfermagem e Cuidar, Cuidado Humano, Cuidar em Enfermagem, Educação/Processo Educativo e Cuidar em Enfermagem Psiquiátrica.

\section{A REFLEXÃO EM DINÂMICA DE GRUPO: UM CAMINHO CRIATIVO PARA O ENVOLVIMENTO DAS PARTICIPANTES NO PROCESSO DE CONSTRUÇÃO}

Este estudo foi realizado através de uma abordagem qualitativa de natureza metodológica viabilizada pelo processo de reflexão em dinâmica de grupo. Participaram do estudo seis enfermeiras chefes de unidades hospitalares de uma instituição psiquiátrica hospitalar pública, de pacientes psiquiátricos de longa permanência (anteriormente conhecida como Colônia Juliano Moreira), localizada no Rio de Janeiro.

0 processo reflexivo desenvolvido foi inspirado em Paganini ${ }^{11}$, com acréscimo da dinâmica de grupo. Facilitadora e participantes ponderaram em conjunto sobre a essência do cuidar em enfermagem; foram proporcionadas às integrantes chances para manifestarem seus sentimentos, algumas vezes ainda desconhecidos ou não declarados, guiando-as para um aprendizado compartilhado e dividindo emoções, o que as fez refletir sobre si mesmas, buscando o autoconhecimento e, naturalmente, amadurecimento. A dinâmica de grupo é uma maneira de confrontar e suplantar o afastamento e alheamento do indivíduo. 0 homem, enquanto membro da sociedade, está sempre participando e convivendo em atividades sociais grupais, seja na família, escola ou trabalho, onde lhe infligem respostas que restringem ou incrementam. Através da dinâmica de grupo, desenvolvemos ponderação, escuta e relação dialógica em que a enfermeira deve se basear [...] para fazer algo mais, para fazer melhor e de modo diferente, o estar próximo, o estarjunto, a presença $[. . .]^{2}$, e são formas de cuidado que se manifestaram durante o processo de construção do marco referencial, pois trabalhando juntos abrem-se novos caminhos.

Atendo-se aos preceitos da ética (Resolução 196/96), elaboramos o Consentimento Livre e Esclarecido, e cada enfermeira autorizou por escrito o documento. A partir da autorização, foram realizadas a gravação em fita magnética e posterior transcrição de suas falas ocorridas durante os encontros. Os textos transcritos foram submetidos à validação de cada uma das participantes. A fim de preservar o anonimato, as participantes foram identificadas por codinomes de flores diversas. Somente a autora deste estudo teve acesso aos documentos originais, a fim de acompanhar o processo, em um período relativamente longo, que exigia a identificação. Para a coleta de dados, foram realizados nove seminários no horário de trabalho, com duração média de cento e vinte minutos cada um. Os temas discutidos foram previamente estabelecidos. Denominaram-se seminários os encontros agendados com as participantes e que se realizaram em ambiente apropriado para facilitação da discussão dos temas que fundamentaram a construção do referencial teórico-filosófico. Os temas selecionados para serem desenvolvidos nos seminários tiveram como base as crenças, a prática e a vivência dos sujeitos, combinadas aos conceitos previamente estabelecidos e anteriormente mencionados, além de outras ideias que surgiram a partir de vários autores ${ }^{5,6-10,14)}$.

$\mathrm{Na}$ pesquisa foram buscados caminhos alternativos, estabelecendo a relação dialógica, visando o chamamento do grupo para interação, discussão e reflexão em um processo contínuo que permeou todos os momentos vividos durante o processo. 0 apoio no referencial adotado trouxe como consequência a necessidade individual de desenvolver e exercitar novos hábitos e postura profissional.

\section{ANÁLISE E DISCUSSÃO DOS RESULTADOS}

$\mathrm{Na}$ análise dos dados, articularam-se três áreas conceituais empregadas no suporte teórico do estudo, representadas na Figura 1. As forças antagônicas da Teoria do Cuidado Burocrático ${ }^{3}$ estavam presentes na instituição asilar, porém, a fundamentação para a prática do Cuidar em Enfermagem para pacientes de longa permanência institucionalizados uniu conceitos da Teoria Humanística ${ }^{2}$, diretrizes da Reforma Psiquiátrica e novas Políticas de Saúde Mental - de uma prática transformadora e com participação ativa do sujeito.

Figura 1: Articulação das três áreas conceituais utilizadas no suporte teórico.

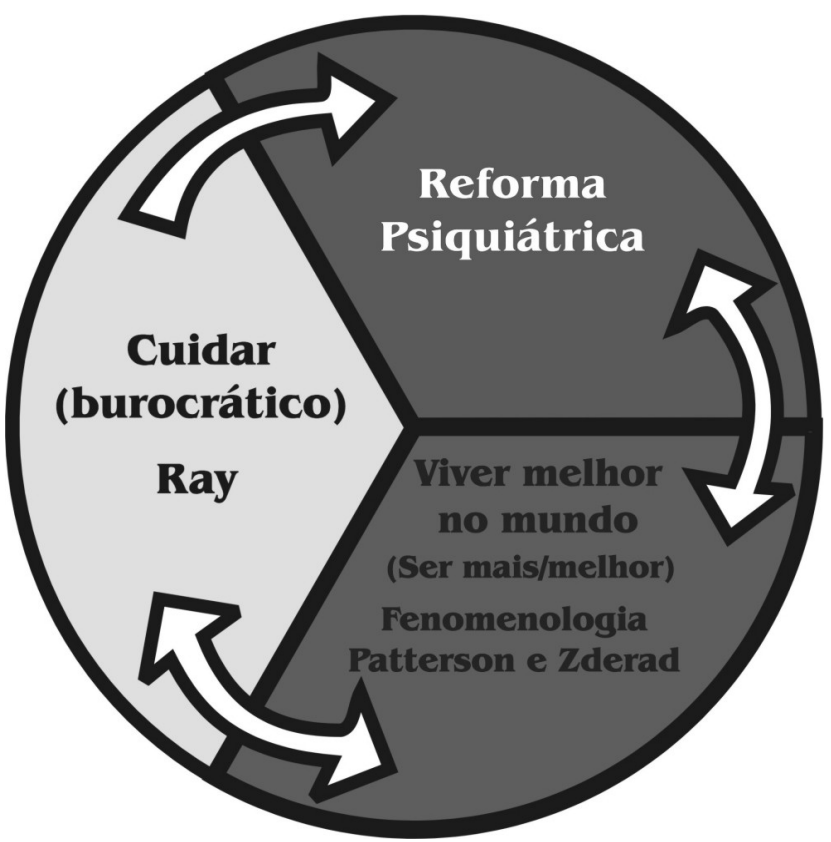

Fonte: Neves (2002). 
Os resultados destacaram categorias acerca de: Concepções sobre o Ser Humano - ser humano é um complexo de emoções, uma pessoa em permanente crescimento, desenvolvimento e aprimoramento. Possuiu suas próprias crenças, valores e conhecimentos, tornando-se único, integral e total; Concepções sobre o cuidado profissional de Enfermagem - cuidar é garantir assistência integral, dando o melhor de si, e o cuidado humano, enquanto ato e atitude humana surgem das interações subjetivas de nutrir, ajudar o outro a crescer, crescer com o outro, buscar 0 autoconhecimento, unir, confiar, amparar o ser cuidado, resgatar autonomia, estimular o autocuidado, respeitar individualidade, vontade, desejo, interagindo, sendo um agente terapêutico, valorizando os sentimentos, crenças e valores; Concepções sobre o cuidado ao cuidador profissional - 0 enfermeiro, enquanto facilitador do cuidado, ao relacionar-se, utiliza habilidades clínicas de maneira terapêutica para perceber significados, através de gestos, olhares e toque, numa visão completa do ser. Nesse papel, ele pode possibilitar a criação de um espaço onde a equipe de enfermagem tem possibilidade de colocar seus problemas e angústias já que a relação do cuidar é uma troca de sentimentos, um compartilhar, uma transação subjetiva em que são respeitados conceitos, pensamentos, valores e culturas, em suas diferenças. Para isso, podemos lançar mão da relação de ajuda, construída e fundamentada na interação do enfermeiro com a equipe de enfermagem, despontando como processo de transformação mútua pautada em ações participativas e enriquecedoras; Concepções sobre o cuidar como processo educativo - no ambiente institucional, individual ou coletivamente, o processo educativo pode ser um instrumento de capacitação para fortalecimento das relações entre as pessoas, aumentando a capacidade de enfrentar situações com mais autonomia e segurança; Concepções sobre o cuidado institucional - os cuidadores há algum tempo atrás, consideravam o paciente de longa permanência institucionalizado um ser passivo que meramente recebia cuidado. Entretanto, com as mudanças advindas da Reforma Psiquiátrica e dos novos projetos desenvolvidos na Instituição, vislumbra-se maior conscientização por parte desse grupo para um cuidado de qualidade, respeitando o espaço e as escolhas do paciente, com vistas a estimular qualquer grau de autonomia possível e ainda existente para realização do autocuidado, num processo construtivo; Concepções sobre o descuidado ao cliente - na instituição onde a estrutura organizacional não é bem delimitada, a indefinição de papéis, sobrecarga burocrática (sinônimo de preenchimento de papéis, fichas) e apego exagerado às rotinas e procedimentos levam ao cerceamento do potencial de criatividade do enfermeiro, afastando-o do cuidado direto. Assim, o enfermeiro assume a posição de gerente da assistência de enfermagem e da organização burocrática institucional, controlando e gerenciando os que vão executá-lo. Todavia, tem sua participação reduzida nos novos dispositivos terapêuticos (passeios, reuniões de miniequipe, tardes dançantes, oficinas, assembleias, entre outros).
Os pressupostos teórico-filosóficos da Teoria Humanística guiaram e auxiliaram na fundamentação do cuidado, já que sabemos o que estamos fazendo e por que, ajudando na troca de experiências, através do autoconhecimento e dos nossos limites.

Considerando o cuidar como uma relação interpessoal, principalmente na área psiquiátrica, é importante evidenciar e reconhecer esses comportamentos, compreender as ações e reações da equipe de enfermagem envolvidas no cuidado e estabelecer uma relação de confiança mútua para reflexão e troca de informações, resgatando o equilíbrio nos momentos de necessidade, que facilitarão a interação no processo de cuidar.

É necessário estimular, como fator motivacional, a transformação da própria prática. Ao atuarmos na área psiquiátrica, necessitamos ter iniciativa, acesso ao conhecimento, reflexão sistematizada, autoconhecimento e conhecimento do outro para estabelecimento de relação consigo e com o outro.

0 movimento de mudança iniciou-se no campo da prática (local da pesquisa), fundamentou-se com o suporte teórico das teorias Humanística e do Cuidado Burocrático ${ }^{2,3}$ e em diversos autores contemporâneos que abordam o cuidar (busca de conhecimento), na realização deste estudo (produção de conhecimento), para posterior retorno e aplicabilidade na prática (intervenção - ação terapêutica).

É importante salientar que o estado de saúde do sujeito vai depender do seu estilo de vida, das condições ambientais, psicológicas e biológicas, assim como das instituições em que se opera o cuidado ${ }^{15}$.

\section{ALGUNS PONTOS PARA REFLEXÃO}

Durante o processo de reflexão em dinâmica de grupo, surgiram vários questionamentos, que levaram o grupo pesquisado e esta autora a refletir sobre crenças pessoais, valores e experiências a respeito do ser humano - paciente psiquiátrico, saúde/doença/saúde mental, IMASJM/ambiente/ sociedade, cuidado humano, enfermagem, educação/processo educativo, cuidar e o modelo que permeava a prática desenvolvida pela Enfermagem na Instituição. A instrumentalização para o cuidar, além de outros aspectos inclui o fortalecimento da habilidade em estabelecer relação de ajuda. Esta, estabelecida pelo o grupo, ocorreu a partir do estímulo desta autora e facilitadora, favorecendo a interação, através de um diálogo estruturado. Foram abordados assuntos determinados (cuidado humano), com objetivos específicos (humanização da prática pelo cuidado).

Para que a relação de ajuda se desenvolvesse de forma adequada, foi necessário ocorrer empatia e estabelecer elo de confiança entre o grupo. Com a empatia, a facilitadora/autora conseguiu perceber adequadamente 0 sentimento individual dos elementos do grupo no desconectar de valores, crenças e opiniões pessoais para ajudar recíproca. A partir deste processo 
de reflexão do grupo de enfermeiras, da fundamentação em conceitos da Teoria da Enfermagem Humanística², da leitura de alguns autores que abordam o cuidar e da análise dos dados, foi construído um marco de referência, submetido à validação das enfermeiras do estudo.

Entendo como referencial teórico-filosófico uma representação que propõe alternativas que fundamentam e dão sustentação ao caminhar, capaz de orientar o processo para a prática do Cuidar em Enfermagem.

Esse referencial teórico-filosófico aspira propor subsídios para atingir a desejada e idealizada transformação e humanização do cuidar de pacientes psiquiátricos de longa permanência institucionalizados. Esse cuidar, ao mesmo tempo

\section{REFERÊNCIAS}

1. Santos ACCF. Construindo um referencial de cuidar em enfermagem psiquiátrica: um processo de reflexão de um grupo de enfermeiras. [dissertação de mestrado]. Rio de Janeiro (RJ): Faculdade de Enfermagem/UFRJ; 2002.

2. Paterson J, Zderad L. A teoria da prática humanística de enfermagem: síntese e interpretação de Nancy 0"Connor. In: McQuinston CMW, Adele A. Foundations of nursing theory: contributions of 12 key theorists.London(UK): Thousand Oaks, Sage publications; 1995. p. 317-68. Texto traduzido para uso didático por Eloita Pereira Neves. FENF/UERJ; 2001.

3. Ray MA. The theory of bureaucratic caring for nursing pratice in the organizational culture. Nurs Administr Quarterly 1989; 13(2): 31-42. Texto traduzido para uso didático por Beatriz Cristina Cardoso Fontes dos Santos. Rio de Janeiro(RJ); 2002.

4. Bardin L. Análise de conteúdo. Lisboa (P0): Ed 70; 2004.

5. Mayeroff M. A arte de servir ao próximo para servir a si mesmo. Tradução de Cristina Carvalho Boselli. Rio de Janeiro (RJ): Record; 1971.

6. Neves-Arruda E, Marcelino SR. Cuidando e confortando. In: Nascimento-Shulze, CM. Dimensões da dor no câncer: reflexões sobre o cuidar interdisciplinar e um novo paradigma da saúde. São Paulo (SP): Robe; 1997. . $157-89$.

7. Neves-Arruda E, Nunes AMP. Confor to em enfermagem: uma análise teórico-conceitual. Texto\&Contexto Enferm 1998 maio/ago;7(2): 93110. em que se apresentava sem concepções teórico-filosóficas e operacionais formais, também se constituía, por parte das enfermeiras, em preocupação, interesse, respeito e valorização ao ser cuidado.

Apresento uma proposta de referencial para a prática do Cuidar em Enfermagem a pacientes psiquiátricos de longa permanência institucionalizados, cujos pressupostos se constituem na expressão da maneira de ser, sentir, pensar e agir do grupo de enfermeiras participantes, reconhecendo 0 desafio de encontrar formas para estimular as forças que impulsionam e enfrentar aquelas impeditivas que atuam simultaneamente no desenvolvimento do processo de trabalho na instituição.

8. Waldow VR. Examinando o conhecimento na enfermagem. In: Waldow V, Lopes MJM, Meyer ED. Marcas da diversidade: saberes e fazeres da enfermagem contemporânea. Porto Alegre (RS): Artes Médicas; 1998.

9. Waldow VR. Cuidado humano: o resgate necessário. Porto Alegre (RS): Sagra Luzzatto; 1999.

10. Waldow VR. 0 cuidar humano: reflexões sobre o processo de enfermagem versus processo de cuidar. Rev Enferm UERJ 2001 set/ dez; 9 (3): 284-93.

11. Silva AL. A dimensão humana do cuidado em enfermagem. Acta Paul Enferm 2000; 13( n esp p1): 86-90.

12. Stefanelli MC. Comunicação com paciente: teoria e ensino. São Paulo (SP): Robe; 1993.

13. Travelbee J. Intervencion en enfermeria psiquiátrica. Cali (CO): OPAS/OMS; 1982.

14. Paganini MC. Humanização da prática pelo cuidado: um marco de referência para a enfermagem em unidades críticas. [dissertação de mestrado]. Curitiba (PR): UFSC / UFP/Convênio Repensul; 1998.

15. Silva DC, Alvim NAT, Figueiredo PA. Tecnologias leves em saúde e sua relação com o cuidado de enfermagem hospitalar. Esc Anna Nery Rev Enferm 2008 jun; 12(2): 291-98. 